\title{
A FORMAÇÃO DO NUTRICIONISTA SOB A PERSPECTIVA DO CURRÍCULO EM SAÚDE $^{(a)}$
}

\author{
THE FORMATION OF NUTRITIONISTS IN THE HEALTH CURRICULUM \\ PERSPECTIVE
}

\author{
Ingrith Raphaelle Rodrigues Calças ${ }^{(b)}$ \\ Kátia Gianlupi ${ }^{(\mathrm{c})}$ \\ Lourdes Missio $^{(\mathrm{d})}$ \\ Márcia Regina Martins Alvarenga ${ }^{(\mathrm{e})}$
}

\begin{abstract}
Resumo
Objetivou-se abordar a constituição histórica dos cursos de nutrição e descrever como as bases legais influíram nas mudanças no âmbito do ensino, à luz da temática do currículo.Realizou-seuma pesquisa bibliográfica exploratória utilizando o Projeto Político Pedagógico de um curso de nutrição,documentosoficiais e artigos científicos. Apreende-se que o processo de formação dos nutricionistas foi conduzido por mudanças legais moldando um perfil condizente às necessidades sociais e que contemplasse as habilidades pertinentes para sua atuação. As transformações do currículo de nutrição, permitiram seu aprimoramento de forma a implementar o perfil profissional com ênfase no atendimento integral à populaçãoe também à atuação em outras áreas, entre as quais a docência, local em que o mesmo também pode ser inserido, em consonância com o postulado pelas Diretrizes Curriculares Nacionais para a área.
\end{abstract}

Palavras-chave: Currículo. Nutricionista. Ensino. Saúde.

\begin{abstract}
This work has aimed to approach the historical constitution of nutrition courses and describe how the legal bases have influenced the changes in teaching, through the curriculum theme. A bibliographic exploratory research has been conducted by using the Pedagogical Political Project of a nutrition course, official documents and scientific articles. It apprehends that the process of training nutritionists has been conducted by legal changes shaping a suitable profile to social needs that contemplates relevant skills for their acting. The changes in nutrition curriculum have allowed its improvement in order to implement the professional profile with emphasis on comprehensive care to the population and also to the performance in other areas, including teaching, where it can also be inserted, in consonance with the one postulated by the National Curriculum Guidelines for this area.
\end{abstract}

Keywords: Curriculum. Nutritionist. Teaching. Health.

\footnotetext{
${ }^{(a)}$ Este artigo é decorrente de uma avaliação parcial da disciplina de Currículo em Saúde do Programa de Pós-graduação Mestrado Profissional Ensino em Saúde da Universidade Estadual de Mato Grosso do Sul (UEMS).

(b) Enfermeira, mestranda do Programa de Pós-graduação Mestrado Profissional Ensino em Saúde da Universidade Estadual de Mato Grosso do Sul (UEMS).E-mail: ingrith_raphaelle@hotmail.com

${ }^{(c)}$ Nutricionista , mestranda do Programa de Pós-graduação Mestrado Profissional Ensino em Saúde da Universidade Estadual de Mato Grosso do Sul (UEMS). E-mail: katiagianlupi@hotmail.com

(d)Doutora em Educação, Professora do Curso de Enfermagem da Universidade Estadual de Mato Grosso do Sul (UEMS), colaboradora do Programa de Mestrado em Enfermagem da Universidade Federal de Mato Grosso do Sul (UFMS) e DocentePermanente do Programa de Pós-graduação Mestrado Profissional Ensino em Saúde da Universidade Estadual de Mato Grosso do Sul (UEMS). E-mail: lourdesmissio@uems.br

${ }^{(e)}$ Doutora em Enfermagem, Professora adjunta do Curso de Enfermagem da Universidade Estadual de Mato Grosso do Sul (UEMS), docente Permanente do Programa de Mestrado em Enfermagem da Universidade Federal de Mato Grosso do Sul (UFMS) e do Programa de Pósgraduação Mestrado Profissional Ensino em Saúde da Universidade Estadual de Mato Grosso do Sul (UEMS). E-mail:marciaregina@uems.br
} 


\section{Introdução}

A presente pesquisa tem como tema o currículo em saúde, mais especificadamente o curso de nutrição, com enfoque para as diretrizes curriculares nacionais do referido curso e o projeto político pedagógico de uma instituição pública de ensino superior.

Os objetivos deste artigo foram: abordar a constituição histórica dos cursos de nutrição e descrever como as bases legais influíram nas mudanças no âmbito do ensino, envolvendo a temática do currículo em saúde.

A escolha deste temamostra-se relevante, uma vez que, nos últimos anos, as questões curriculares dos cursos superiores de graduação têm sido amplamente debatidas pela sua relevância e atualidade, considerando, ainda, a revolução do conhecimento, a disponibilidade de informações e a velocidade com que estas se tornam ultrapassadas, demandando, assim, a formação de profissionais com competências para acompanhar todo este desenvolvimento intelectual.

Assim, sua análise e discussão poderão fomentar novas possibilidades de construção de propostas pedagógicas, permitindo uma formação integral e satisfatória para a atuação.

Outro aspecto relevante, diz respeito às mudanças no mundo do trabalho, em que o conhecimento recebe valor de mercadoria diante do regime capitalista, o que impõe uma reformulação nos processos de formação dos profissionais da saúde ${ }^{1 .}$

O termo currículo se origina do latim curriculum que significa carreira, curso ou o ato de correr e pressupõe a forma de se efetuar um percurso ${ }^{2}$. No entanto, de forma tradicional, ele se manifesta na relação de disciplinas ou matérias de determinado curso onde se lista os conteúdos a serem transmitidos de forma programática aos alunos ${ }^{3}$. A palavra currículo pode ser entendida também como a cultura da própria escola, as quais estão fortemente relacionadas às condições institucionais refletidas na política curricular, na estrutura e na organização do curso e resulta das concepções curriculares vigentes ${ }^{4}$.

Até a década de 80, a configuração do currículo era mais voltada para o ensino técnico, com foco na atenção individual em detrimento ao coletivo, evidenciando um nítido distanciamento das reais necessidades da sociedade. Portanto, é imprescindível compreender este processo de formação profissional como prática social, diante do seu papel na constituição da sociedade capitalista e que considere o território sob sua abrangência, atuando sob a ótica da intersetorialidade, tão fundamental para o enfrentamento da complexidade dos problemas de saúde e de nutrição da população ${ }^{5}$. 
Pode-se dizer que o currículo é construído a partir de um processo histórico e social de múltiplas transformações, as quais lhe dão sua caracterização particular. Nesta perspectiva, o currículo se divide em interdisciplinar e integrado. Currículo integrado é definido como um conjunto de determinados "módulos", os quais substituem o termo "displinas", que estão interligados e são interdependentes, representando um modelo contemporâneo que articula trabalho e ensino, prática e teoria, ensino e comunidade ${ }^{6}$.

O currículo em saúde (formação dos profissionais da saúde) passou por intensas transformações. Inicialmente, este processo foi influenciado pelo modelo flexneriano, baseado na fragmentação do conhecimento, que cultuava o tratamento da doença em contraposição à promoção da saúde e que utilizava metodologias tradicionais de ensino, onde o aluno era apenas receptor do conhecimento. Esse modelo foi paulatinamente sendo superado por meio da implementação de metodologias ativas de ensino-aprendizagem, em que o aluno transforma-se no construtor ativo do seu próprio conhecimento. Alguns movimentos nacionais e internacionais foram os propulsores desta nova perspectiva: a Reforma Sanitária, a VIII Conferência Nacional de Saúde, a Lei Orgânica de Saúde, a XIX Conferência Nacional de Saúde, a Network of Community-oriented Educational Institutions for Health Sciences (NETWORK), o programa UNI e a participação de classes sociais organizadas, revigorados pelas Diretrizes Nacionais dos cursos da área da saúde ${ }^{6}$.

Desta forma, as instituições de ensino em Nutrição deveriamformarum profissional com perfil que atendesse às exigências da nova configuração de atenção à saúde. Diante disso, é preciso que o currículo na área da nutrição considere o perfil epidemiológico vigente no Brasil e no mundo, que, nos últimos anos, demonstra a concomitância entre desnutrição e excesso de peso em regiões e populações específicas ${ }^{7}$.

A expansão do número de cursos de Nutrição no Brasil se deu a partir da instituição da Lei $n^{\circ}$ 9.394, de 20 de dezembro de 1996, que estabelece as Diretrizes e Bases da Educação Nacional (LDB) e, posteriormente, a formação passou a serdirecionada pela Resolução CNE/CES no 5, de 7 de novembro de 2001, a qual instituiu as Diretrizes Curriculares Nacionais do Curso de Graduação em Nutrição ${ }^{8,9}$.

Com essa notória expansão, se faz necessária a formação de docentes que atuemnessas instituições. No entanto, apesar de a docência constituir uma das áreas de atuação do profissional nutricionista, nota-se ausência deste enfoque durante sua formação e também em outros cursos superiores na área da saúde, já que este campo de trabalho é considerado por 
muitos profissionais como uma opção secundária, o que justifica a denominadadesprofissionalização (falta de formação pedagógica) dos mesmos ${ }^{10}$.

Atualmente, há uma intenção de mudança neste aspecto, tendo em vista que as modificações que vêm se estabelecendo no mundo do trabalho exigemcompetências consideradas como incoerentes com o método de ensino-aprendizagem que é desenvolvido nas instituições de ensino superior, em que há a reprodução do método pelo qual seus docentes foram formados. No entanto, as Diretrizes Curriculares Nacionais (DCN) fazem referência às necessidades emergentes na área de ensino, em que o professor deve representar um mediador do processo ensino-aprendizagem e ter o aluno como o centro de suas estratégiaseducativas $^{11}$.

Remetendo agora aos campos de atuação, há um notório destaque para o da saúde pública. Estudodesenvolvido com professores, estudantes e recém-egressos do curso de nutrição evidenciou que um dos grandes problemas para o perfil que está se estabelecendo para este profissional atuante neste cenário é a linearidade do ensino. Este por sua vez, preconiza primeiramente a teoria e por fim a prática, geralmente efetivada tardiamente na estrutura curricular, bem como ànatureza biologicista e fragmentada do referido curso, no qual as disciplinas relacionadas ao aspecto social da saúde somente são inseridas nos últimos anos. Deixa-se nítido a tentativa de rompimento com a visão biológica dos alunos e a necessidade de readequações e modificações neste currículo afim de atender às exigências do mercado de trabalho ${ }^{12}$.

\section{Método}

Utilizou-se o método da pesquisa bibliográfica exploratória, tendo como foco a temática do currículo em saúde, primordialmente, o do curso de nutrição. Neste tipo de pesquisa,oautor pretende familiarizar-se com um assunto ainda pouco conhecido por ele ou raro em questões de exploração científica ${ }^{13}$. Pretendeu-se então conhecer mais a fundo o tema e estruturar hipóteses a respeito dele a partir de um levantamento bibliográfico.

Esta pesquisa representa uma das atividades da disciplina de Currículo em Saúde do Programa de Pós-graduação, Mestrado Profissional em Ensino em Saúde da Universidade Estadual do Mato Grosso do Sul (UEMS).

Foram pesquisados documentosoficiais para análise, incluindo o projeto político pedagógico de um curso de nutrição de uma universidade pública do estado de Mato Grosso do Sul;a Lei $\mathrm{n}^{\circ} 9.394$ de 20 de dezembro de 1996que estabeleceu as diretrizes e bases da 
educação nacional; o Parecer $\mathrm{n}^{\circ} 1.133$ de 7 de agosto de 2001, que postula as diretrizes curriculares nacionais dos cursos de graduação em enfermagem,medicina e nutrição; a Resolução do Conselho Nacional de Educação/Câmara de Educação Superior $n^{\circ} 5$ de 7 de novembro de 2001 que instituiu as diretrizes curriculares do curso de graduação em nutrição; o Parecer $\mathrm{n}^{\mathrm{o}} 2$ de 10 de fevereiro de 2009 que aborda a carga horária mínima de cursos bacharelados da saúde na modalidade presencial, além de artigos científicos e outros materiais bibliográficos que abordam a temática de formação na respectiva área.

A seleção se deu levando em consideração o ano de publicaçãoea relação com o tema central do estudo, os textos que apareceram em duplicatas tiveram uma de suas versões excluída. Os critérios de inclusão para a seleção desses estudos foi que estes estivessem sidos publicados a partir do ano de 2002, levando em consideração as transformações no currículo do curso envolvido na pesquisa, tenham sidos publicados no Brasil,em língua portuguesa, completos e disponíveis online.

Os textos científicos foram selecionados na base de dados Scielo e Bireme, utilizando os seguintes descritores: nutrição e currículo; nutrição; e formação do nutricionista. De acordo com os descritores citados foram encontrados respectivamente, 5 (cinco) artigos dos quais foram selecionados 2 (dois), 43 (quarenta e três) encontrados sendo 4 (quatro) escolhidos e, por fim 532 (quinhentos e trinta e dois) selecionados 5 (cinco).

Após leitura prévia dos resumos, totalizou-se 11 artigos completos e de livre acesso, que foram selecionados durante o período de abril a julho de 2014.

Todos os documentos foram submetidos à leitura para síntese e composição da pesquisa.

\section{Resultados e Discussão}

O surgimento dos cursos de nutrição na América Latina relaciona-se com a fundação do Instituto Nacional de Nutrição e da Escola de Dietistas no ano de 1933, na capital da Argentina, a cidade de Buenos Aires. O pioneiro foi o médico argentino Pedro Escudero. No Brasil esse surgimento se deu entre os anos de 1930 e $1940^{14}$.

A nomenclatura adotada para denominar os profissionais nutricionistas foi empregada no Brasil conjuntamente com o primeiro curso criado em 1939 pelo Instituto de Higiene, atualmente Faculdade de Saúde Pública da Universidade de São Paulo ${ }^{7}$. Em anos posteriores e após a criação do primeiro curso houve o surgimento de mais seis em todo o Brasil e apenas em instituições públicas. 
A graduação em nutrição surgiu a partir dos cursos técnicos de nutricionistas-dietistas, reconhecido pelo Parecer no 265 de 19 de outubro de 1962 que ainda implementou o currículo mínimo. A regulamentação desta profissão veio em 24 de abril de 1967 com a promulgação da Lei $n^{\circ} 5.276$, com o curso de três anos de duração ${ }^{15}$, sendo substituída pela Lei $n^{\circ} 8.234$ de 17 de setembro de $1991^{16}$.

No ano de 1960, o Conselho Federal de Educação (CFE) propôs a fixaçãodo currículo mínimo para os cursos de graduação do país, instituindo que este deveria ser estruturado por matérias que se desdobrariam em disciplinas paracompô-lo. Estabelecendo dessa forma, currículos homogêneos para os cursosde ensino superior oferecidos em cada instituição, com o intuito de garantir um mínimo qualitativo na formação do profissional ${ }^{3}$.

Conjuntamente com esse advento houve também o surgimento de duas correntes de saber científico neste campo de conhecimento, uma biológica e a outra relacionada à produção agrícola. Na primeira abordagem o enfoque era para o consumo propriamente dito de alimentos e à utilização biológica dos nutrientes, conceitos estes influenciados pelas escolas norte-americanas e europeias de nutrição, que viriam a contribuir para a formação dos campos da nutrição básica, experimental e clínica ${ }^{14}$.

Já na segunda corrente, o destaque era para os aspectos de distribuição e consumo alimentar, que posteriormente seria o núcleo da nutrição social, com atuação voltada ao coletivo e aos aspectos econômicos do processo alimentar. Essa perspectiva contribuiu para a origem da área tanto de alimentação coletiva ou institucional, quanto de nutrição em saúde pública $^{14}$.

Em 1970, observou-se uma grande expansão do número de cursos de nutrição em universidades públicas. No entanto este crescimento se deu de forma desordenada, tendo em vista que não havia uma estratégia ou projeto político que direcionasse esses $\operatorname{cursos}^{8}$. Na mesma década, no ano de 1974, o Conselho Federal de Educação estipulou o segundo currículo mínimo com a fixação de uma carga horária de 2.880 horas divididas em quatro $\operatorname{anos}^{15}$.

A partir daí, o currículo mínimo da nutrição passou a serrevisado, pois, entendia-se que este não acompanhava o desenvolvimento técnico e científico, visto que era considerado excessivamente carregado teoricamente e sem flexibilidade. Não levava em consideração aindividualidade territorial, das instituições formadoras, das graduações ofertadas e ainda as necessidades da sociedade como um todo, tendo em vista que existem diversas desigualdades e peculiaridades. Além desses inconvenientes, não era estabelecido um estímulo à aquisição 
de novos saberes e a anexação de novas tecnologias no âmbito do ensino. Outro ponto desfavorável era que o aluno seria visto como coadjuvante de sua própria formação, desconsiderando a sua aprendizagem participativa ${ }^{5}$.

O currículo constituía-se como uma relação ou sucessão de disciplinas ou matérias de determinado curso onde se lista os conteúdos a serem transmitidos de forma sequencial aos alunos.As críticas a esse modelo se estenderam por décadas, até mesmo porque as reformas propostas e efetivas não foram suficientes para produzir mudanças contundentes.

Entre os anos de 1970 e o de 1996 existiam um total de 15 cursos públicos e foram criados mais 23 em instituições particulares. Depois de 1996 e até o ano de 2005existia, 45 cursos no país, esse aumento significativo se deu devido à promulgação da Lei de Diretrizes e Bases da Educação Nacional (LDB), em substituição ao currículo mínimo ${ }^{6}$. Vale ressaltar que a LDB atribui às universidades a função de "fixar os currículos dos seus cursos e programas, conformeas diretrizes gerais pertinentes" em seu artigo 53 parágrafo II $^{8}$.

Tal promulgação foi uma modificação importante para a substituição do currículo mínimo pelas novas diretrizes curriculares, permitindo a configuração de um modelo acadêmico e, futuramente profissional, com disciplinas e competências condizentes com o perfil mais moderno, que primordialmente deve ser comprometido com a promoção de práticas e hábitos alimentares saudáveis ${ }^{7}$.

Ainda, no sentido de buscar mudanças nos moldes anteriormente existentes, através do Parecer $n^{\circ} 1.133$ de 26 de junho de 2001 do Conselho Nacional de Educação, o Ministério da Educação apresentou de forma preliminar as diretrizes curriculares para os cursos de medicina, enfermagem e nutrição, este sancionado em 7 de agosto de $2001^{9}$. Com a sistematização das sugestões apresentadas, posteriormente, esse parecer foi transformado na Resolução $\mathrm{n}^{\circ} 5$ de 2001, que institui as Diretrizes Curriculares Nacionais do curso de graduação em nutrição. Esta Resolução deve ser atendida para a elaboração do currículo do curso em todas as instituições de ensino superior em substituição ao currículo mínimo. No quesito perfil profissional, o artigo $3^{\circ}$ estabelece:

nutricionista, com formação generalista, humanista e crítica, capacitado a atuar, visando à segurança alimentar e à atenção dietética, em todas as áreas do conhecimento em que a alimentação e nutrição se apresentem fundamentais para a promoção, manutenção e recuperação da saúde e para a prevenção de doenças de indivíduos ou grupos populacionais, contribuindo para a melhoria da qualidade de vida, pautado em princípios éticos, com reflexão sobre a realidade econômica, política, social e cultural ${ }^{9}$. 
Nos $\operatorname{artigos} 4^{\circ}$ e $5^{\circ}$ são retratadas algumas competências e habilidades gerais e específicas para o exercício da profissão do nutricionista. Nestes parágrafos, há a atenção à saúde para o desenvolvimento de ações de prevenção, promoção, proteção e reabilitação da saúde em nível individual e coletivo; tomada de decisões para avaliar, sistematizar e decidir as condutas mais adequadas; habilidade de comunicação (verbal, não verbal, escrita e leitura); liderança no trabalho em equipe multiprofissional; administração e gerenciamento das forças de trabalho,recursos físicos e materiais e de informação e por fim educação permanente fazendo com que estes estejam aptos aaprender continuamente ${ }^{9}$.

As inovações apresentadas pelas Diretrizes Curriculares Nacionais incluem: incitação à participação em atividades complementares que deverão acontecer no decorrer do curso, maneira flexível de oferta das disciplinas, inovações na gestão dos cursos tendo em sua elaboração a participação na construção dos projetos políticos pedagógicos e por fim uma distribuição igualitária da carga horária de estágiospelas três principais áreas de atuação do nutricionista 4 .

As diretrizes trouxeram um novo vislumbre ao perfil do profissional, aos princípios que regeram sua prática e ainda a descriminação das competências e habilidades que são primordiais aos nutricionistas. Estas por sua vez, definem os princípios, fundamentos, condições e procedimentos da formação, bem como a organização, desenvolvimento e avaliação dos projetos políticos pedagógicos dos cursos.

Toda essa adequação curricular proporcionou o aumento da oferta de cursos de graduação em todo território nacional. Assim, a expansão se deu prioritariamente no setor privado, no entanto, no ano de 2003 houve também a criação de considerável número de vagas em instituições públicas. Apreende-se que houve o aumento do número de cursos em regiões mais interioranas ${ }^{15}$.

Em 2006 eram 269 (duzentos e sessenta e nove) ao total. No ano de 2009 havia 67 (sessenta e sete) cursos em Instituições de Ensino Superior (IES) públicas e 324 (trezentos e vinte e quatro) em privadas ${ }^{15}$. Três anos depois em 2012, esse número chegava a 379 (trezentos e setenta e nove) cursos de bacharelado em nutrição, sendo 60 (sessenta) em IES públicas e 319 (trezentos e dezenove) emparticulares ${ }^{7}$.

Estudo realizado no ano de 2012 em Campinas/SP visandocaracterizar os cursos de nutrição no país,demostrou que a maioria se constitui de instituições privadas, obtendo os seguintes resultados: há um grande volume de cursos criados mais recentemente onde os 
formandos concluíram suas atividades de graduação na última década. Quanto à duração, a maioria aconteceu em 8 (oito) semestres,mas,também houveram cursos com 9(nove) e 10 (dez) semestres. Em relação à carga horária encontrou-se uma variação de 3.301 a 3.700 horas. Observou-se que os cursos eram munidos de aproximadamente 40 (quarenta) professores, sendo mais numerosos nas instituições públicas e com formação em nutrição ${ }^{7}$.

Nessa mesma perspectiva analisou-se o Projeto Político Pedagógico (PPP) do curso de nutrição de uma instituição pública do Mato Grosso do Sul. Nele apresenta-se a necessidade social do curso, que se fazia pertinente no estado, poiseste era ofertado apenas por instituições privadas, além de o mercado de trabalho para os profissionais egressos estar em expansão. Outro ponto levado em consideração para a implantação desta graduação foi à transição nutricional pela qual o país está passando, inclusive o estado de Mato Grosso do Sul, mostrando a necessidade do aumento do número de profissionais na região ${ }^{17}$.

A formação do profissional perpassa pelo intuito do embasamento nas concepções de transdisciplinaridade e interdisciplinaridade, com identidade profissional construída nos preceitos, conhecimentos e competência técnica, além da ética, humanização e da formação crítica e reflexiva, buscando as raízes culturais e filosóficas indispensáveis a constituição integral e fundamental do profissional.

A interdisciplinaridade caracteriza-se como a junção de diversos pontos de vista, com a finalidade de construir um objeto teórico comum, já a transdisciplinaridade é uma forma de ultrapassar as fronteiras disciplinares ${ }^{18}$.

O cursoanalisado pretende possibilitar que o indivíduo atue na sociedade e tenha compreensão do seu papel social, alicerçado nas relações interpessoais e das pessoas com o conhecimento, levando em consideração para a formação os valores democráticos e os conceitos de cidadania, avaliação e liberdade na construção de um sujeito crítico, capaz de compreender o contexto histórico-cultural, dar resposta às demandas sociais e ser um agente de transformação na sociedade.

Este curso possui carga horária total de 4.446 horas, já adequado às reivindicações do Conselho Federal de Nutrição que exigiu a incorporação de 4.000 horas, embora a Resolução $n^{\circ} 4$ do Conselho Nacional de Educação (CNE), de abril de 2009, tenha estabelecido carga mínima de 3.200 horas, dispondo ainda a respeito dos procedimentos relativos à integralização e duração dos cursos de graduação da área da saúde.

Outro aspecto interessante é que o PPP traz sua fundamentação legal na Lei de Diretrizes e Bases da Educação Nacional (1996) e Diretrizes Curriculares Nacionais para o 
Curso de Nutrição (2001) e segue as linhas mestras do Projeto Político Institucional (PPI) e do Projeto de Desenvolvimento Institucional (PDI) da instituição em questão, os quais norteiam o futuro da Instituição Federal de Ensino Superior e estabelecem a missão da mesma, focado na indissociabilidade entre ensino, pesquisa e extensão, a gestão democrática, o compromisso social e a gratuidade do ensino ${ }^{17}$.

Ainda com relação à Resolução $n^{\circ}$ 4/2009, esta informa sobre a área de atuação específica dos profissionais egressos, enfatizando que a formação do nutricionista deve considerar as necessidades sociais de saúde focalizados no Sistema Único de Saúde (SUS), o que não está presente de maneira explícita no PPP do curso analisado.

Embora o profissional ainda não esteja completamente inserido na Estratégia Saúde da Família (ESF), este tem sido incorporado ao Núcleo de Apoio à Saúde da Família (NASF) desde 2008, com o objetivo de ampliação das ações da Atenção Básica, visto que a equipe que o constitui é multiprofissional ${ }^{19}$. A presença desse profissional favorece a promoção da saúde da população atendida nos aspectos nutricionais e de alimentação, exigindo deste o aprimoramento e competências que o faça entender a realidade local, dando-o subsídios para o desenvolvimento de ações condizentes com o diagnóstico sociodemográfico ${ }^{20}$.

A formação do nutricionista, como profissional de saúde atuante na área de saúde pública, perpassa pela incorporação dos pressupostos do SUS, atendendo aos preceitos éticos e de cidadania, passandopela compreensão do processo saúde-doença e prestação do cuidado, em consenso com o contexto epidemiológico, considerando a realidade sanitária, social, política e cultural, bem como a diversidade regional da população ${ }^{7}$.

Ainda em consonância com a Resolução $n^{0}$ 5/2001supracitada, no artigo $6^{0}$ é estabelecido que os conteúdos da graduação devem ser enquadrados de acordo com todo o processo de saúde e doença da população,seja de maneira individual ou coletiva, operacionalizado de forma adequada à realidade local proporcionando, assim, uma assistência integrada e ações mais eficazes. A mesma ainda aponta que onutricionista tem a qualificação necessária para atuar nas questões de insegurança alimentar e nutricionais dos diferentes grupos populacionais ${ }^{9}$.

Dessa forma, com o propósito de desenvolver as competências e habilidades necessárias ao egresso, os conteúdosforam distribuídos em grandes áreas: ciências biológicas e da saúde, ciências sociais, humanas e econômicas, ciências da alimentação e nutrição e ciências dos alimentos 9 . 
Avaliando-se a formação em Saúde Pública dos cursos de graduação em nutrição do Brasil, identificou-se quanto às descrições das disciplinas nesta área, que há predominância de 14 (quatorze) disciplinas nos cursos como geral, sendo que algumas são consideradas obrigatórias e foram mais prevalentes na composição do bloco, a exemplo de: avaliação nutricional, educação nutricional, estágio em nutrição social, nutrição em saúde pública, epidemiologia, bioestatística e nutrição materno-infantil ${ }^{6}$. Totaliza-se uma média de 366 horas destinadas à prática, sendo que esta deve estar presente a partir do início e em todo o percurso do curso, permeando toda a formação do profissional, de forma integrada e multidisciplinar. Já com relação aos estágios, recomenda-se que a carga teórica não supere os $20 \%$ (vinte por cento $)^{9}$.

Constata-se na questão teórico-prática a existência deuma dicotomia entre elas, o que pode ser apontado como um quesito conflituoso, já que neste contexto, não se pode priorizar uma ou outra, mas, fazer com que ambas contemplem a formação integral do profissional nutricionista $^{21}$.

Além da carga horária prática ofertada pelas disciplinas, é imprescindível oportunizar aos alunos de participação em atividades complementares, tais como monitorias, estágios extracurriculares, projetos de extensão, cursos em áreas afins entre outros, tendo em vista que a vivência nessas práticas permite formação ampliada e constitui experiência relevante, agregando outros valores à formação ${ }^{7}$. Diante disso, notou-se no PPP da IES estudada, que esta encontra-sevinculada a dois programas: Programa Nacional da Reorientação da Formação Profissional em Saúde (PRÓ-SAÚDE) e o Programa de Educação pelo Trabalho em Saúde (PET - SAÚDE).

O PROSAÚDE é um programa que tem o intuito de articular a formação em saúde com o serviço público de maneira a atender às necessidades da população tanto na formação dos recursos humanos, quanto na produção do conhecimento e atendimento aos usuários, buscando o fortalecimento do SUS, o que vem de encontro às Diretrizes Curriculares Nacionais, pois, incorpora as metodologias ativas de ensino-aprendizagem, contribuindo para a formação integral do aluno ${ }^{22}$.

Já o PET-SAÚDE pretende promover grupos de aprendizagem tutorial na Estratégia Saúde da Família, viabilizando o aperfeiçoamento e especialização em serviço dos profissionais de saúde e possibilitando o contato dos estudantes com o trabalho em Saúde Pública, conforme as necessidades do $\mathrm{SUS}^{23}$. 
Os documentos analisados para a construção deste estudo apontam que há incompatibilidade entre a formação dos profissionais da saúde e as necessidades da sociedade brasileira, tais como: falta de integração entre o ensino básico e o profissionalizante, profissionais mais especializados, dificultando uma abordagem generalista do indivíduo e a fragmentação do ensino em disciplinas distintas, contribuindo para essa formação especializada $^{24}$.

Conjuntamente ao exposto, fica nítida a necessidade de que o currículo contemple as demandas da população em geral e ainda os pressupostos do SUS e que para atender a todas essas especificidades e exigências da formação profissional, torna-se imprescindível o seu contínuo aperfeiçoamento e avaliação de maneira sucessiva e sistemática.

\section{Considerações finais}

No presente estudo teve-se como objetivo abordar a constituição histórica dos cursos de nutrição e descrever como as bases legais influíram nas mudanças no âmbito do ensino, envolvendo ainda a temática do currículo em saúde. Foram analisados documentos referentes a esse processo como, a exemplo, diretrizes curriculares, resoluções e pareceres que permearam essa construção. Após, baseados em todos esses documentos, foi realizada uma análisedo projeto político pedagógico de uma IES pública procurando conhecero que se tem na teoria com o postulado por esse.

Com esta pesquisa podemos perceber diversos aspectos convergentes que permeiam a formação do profissional nutricionista, principalmente no que diz respeito àqueles contemplados no projeto político pedagógico da instituição de ensino superior analisada, bem como nas diretrizes curriculares da área. Esses por sua vez, contribuíram para a construção e organização do currículo que deve atender ao pluralismo preconizado, tendo como foco o atendimento às necessidades do desenvolvimento de habilidades e competências necessárias para a atuação profissional, demandando ainda uma profunda reflexão acerca de seu papel social e de sua inserção nas políticas e programas públicos.

Notamos que o processo de formação dos nutricionistas enfrentou diversas transformações que procuraram moldar o perfil de profissional condizente com as necessidades sociais, e condizendo com todo o contexto histórico político e econômico do país.

E esse processo foi conduzido prioritariamente por mudanças legais nas diretrizes 
curriculares nacionais e também dos cursos de ensino superior, refletindo consequentemente nos projetos políticos pedagógicos das instituições formadoras e na consolidação de seus currículos.

Salientamos que o PPP deverá ser construído coletivamente, centrado no aluno como sujeito da aprendizagem e apoiado no professor como facilitador e mediador do processo ensino-aprendizagem, sendo que as DCN são o instrumento oficial de direcionamento desses para os cursos, devendo ser consideradopara sua criação, avaliação ou reformulação do já existente.

É emergente também a necessidade de reformulação na formação dos docentes, principalmente no que se refere à formação pedagógica dos profissionais atuantes nos cursos de nutrição, reverenciado o seu papel como educador e sua importância para o perfil dos egressos e o desenvolvimento de profissionais com as habilidades necessárias para atuação nos diversos setores e, principalmente na Atenção Básica de Saúde, a qual deve seguir os princípios do Sistema Único de Saúde.

Assim, a formação do nutricionista objetiva contemplar plenamente o que se tem postulado e principalmente o idealizado pelos interessados nesse processo, de maneira a configurar o profissional como indivíduo que precisa saber, saber a fazer e saber a ser, tendo como base o domínio cognitivo. Podemos afirmar isso quando constatamos nitidamente a transformação pelo qual o currículo de nutrição passou e ainda está passando ao longo dos anos, aprimorando-se para implementar adequadamente os perfis profissionais com ênfase no atendimento integral à população e também à atuação em outras áreas, como a docência, em que este possa estar inserido, de acordo com o que postula as Diretrizes Curriculares Nacionais para a área.

Portanto, após as análises e reflexões geradas pelo trabalho aqui desenvolvido tem-se que o currículo é algo mais complexo do que o mero elencar de disciplinas.

\section{Referências}

1. MAIA, J. A. O currículo no ensino superior em saúde. In: BATISTA, N. A.; BATISTA, S. H. (Org.). Docência em saúde: temas e experiências. São Paulo: SENAC, 2004.

2. SOARES, N. T.; AGUIAR AC. Diretrizes curriculares nacionais para os cursos de nutrição: avanços,lacunas, ambiguidades e perspectivas. Revista de Nutrição, v. 23, n.5, p. 895-905, 2010. 
3. SMITH, M. K. Curriculum theory and practice' the encyclopedia of informal education.2000.Disponível em: <www.infed.org/biblio/b-curric.htm>. Acesso em: 02 jun de 2014.

4. SACRISTAN G. El curriculum: una reflexion sobre lapractica. Barcelona: Morata, 1996.

5. TADDEI, J. Á, LANG, R. M. F.; SILVA. G. L.; TOLONI, M. H. A. Nutrição em saúde pública. Rio de Janeiro: Editora Rubio, 2011.

6. BELEI, R. A. Gimeniz-Paschoal SR, Nascimento EN.História curricular dos cursos de graduação da area da saúde. RevistaHistória da Educação, ASPHE/FaE/UFPel, Pelotas, jan/abr. v. 12, n.24, p. 101-120, 2008.

7. RECINE E.; GOMES, R. C. F.; FAGUNDES, A.A.; PINHEIRO, A. R. O.; TEIXEIRA, B. A.; SOUSA, J. S.; TORAL, N.; MONTEIRO, R. A. A formação em saúde pública nos cursos de graduação de nutrição no Brasil. Revista de Nutrição, v.25, n.1, p.21-33, 2012.

8. BRASIL. Presidência da República. Casa Civil. Subchefia para Assuntos Jurídicos. Lei n. 9.394, de 20 de dezembro de 1996. Estabelece as diretrizes e bases da educação nacional, 1996.

9. _. Ministério da Educação e Cultura. Resolução CNE/CES n ${ }^{\circ}$ 5, de 7 de novembro de 2001. Institui diretrizes curriculares nacionais do curso de graduação em nutrição. 2001.

10. COSTA, N. M. S. C. Formação pedagógica de professores de nutrição: uma omissão consentida? Revista de Nutrição. Campinas (SP), v.22, n.1, p. 97-104, 2009.

11. BRASIL. Ministério da Educação. Câmara de Educação Superior. Diretrizes Curriculares Nacionais dos cursos de Graduação em Enfermagem, Medicina e Nutrição. CNE/CES 1.133. 2001.

12. PINHEIRO, A. R. O.; RECINE, E.; ALENCAR, B.; FAGUNDES, A.A.; SOUSA, J. S.; MONTEIRO, R. A.; TORAL, N. Percepção de professores e estudantes em relação ao perfil de formação do nutricionista em saúde pública. Revista de Nutrição. Campinas (SP), v.25, n. 5, p. 631-643, 2012.

13. GIL, A. C. Como elaborar projetos de pesquisa. 5. ed. São Paulo: Atlas, 2008.

14. VASCONCELOS, F. A. G. O nutricionista no Brasil: uma análise histórica. Revista de Nutrição. Campinas (SP), v. 15, n.2, p.127-138, 2002.

15. VASCONCELOS, F. A. G.; CALADO, C. L. A. Profissão nutricionista: 70 anos de história no Brasil. Revista de Nutrição. Campinas (SP), v.24, n.4, p. 605-617, 2011.

16. CONSELHO FEDERAL DE NUTRICIONISTAS. Lei n ${ }^{\circ} 8.234$ de 17 de setembro de 1991. Regulamenta a profissão de nutricionista e determina outras providências. Disponível em: $<$ http://www.cfn.org.br/eficiente/sites/cfn/pt-br/site.php? secao=leis\&pub=95>. Acesso em: 13 jun 2014. 
17. BRASIL. Ministério da Educação. Faculdade de Ciências da Saúde. Universidade Federal da Grande Dourados. Projeto Político Pedagógico do Curso de Nutrição. Faculdade de Ciências da Saúde. Dourados, 2013.

18. SCHRAMM, F. R. As diferentes abordagens da bioética. In: PALÁCIOS, M.; MARTINS, A.; PEGORARO, O. (Org.). Ética, ciência e saúde: desafios da bioética. Petrópolis: Vozes, 2002. p.10-38.

19.BRASIL. Ministério da Saúde. Portaria no 154 de 24 de janeiro de 2008. Cria os Núcleos de Apoio à Saúde da Família (NASF). Brasília: 2008.

20. MANCUSO, A. M. C.; TONACIO. L. V.; SILVA, E. R.; VIEIRA, V. L. A atuação do nutricionista na Atenção Básica à Saúde em um grande centro urbano. Ciência\& Saúde Coletiva. São Paulo (SP), v.17, n. 12, p. 3289-3300, 2012.

21. FRANCO AC, B. M. C. F. Relação teórica-prática no ensino de educação nutricional. Revista de Nutrição. Campinas (SP), v. 20, n. 6, p. 643-655, 2007.

22. BRASIL. Ministério da Saúde. Programa Nacional de reorientação da formação profissional em saúde-Pró-Saúde: objetivos, implementação e desenvolvimento potencial. Brasília: MS; 2007.

23. . Ministério da Saúde. Portaria Interministerial 1802, de 26 de agosto de 2008. Institui o Programa de Educação pelo Trabalho para a Saúde - PET - Saúde. Brasília: 2008.

24. ALBUQUERQUE, V. S. et al. Discipline curricula in the health area: an essay on knowledge and power. Interface-Comunic., Saude, Educ., v. 13, n. 31, p. 261-72, out./dez., 2009. 